\title{
Influência do condicionamento em meio redutor na hidrofobicidade de amostras de pirita e hematita
}

\author{
Influence of the conditioning in reducing \\ medium on the hydrophobicity of \\ samples of pyrite and hematite
}

\begin{abstract}
Thaís Ferreira Marks Brasil Duque ${ }^{1}$, Achilles Junqueira Bourdot Dutra ${ }^{2}$, Marisa Bezerra de Mello Monte ${ }^{3}$
\end{abstract}

\footnotetext{
${ }^{1}$ Centro de Tecnologia Mineral - CETEM - Av. Pedro Calmon, 900, Cidade Universitária - CEP: 21941-908, Rio de Janeiro, RJ. Universidade Federal do Rio de Janeiro - PEMM/COPPE/UFRJ - Centro de Tecnologia - Bloco F, Cidade Universitária - CEP: 21941-972, Rio de Janeiro, RJ e-mail: tduque@cetem.gov.br

${ }^{2}$ Universidade Federal do Rio de Janeiro - PEMM/COPPE/UFRJ - Centro de Tecnologia - Bloco F, Cidade Universitária - CEP: 21941-972, Rio de Janeiro, RJ e-mail: adutra@metalmat.ufrj.br

${ }^{3}$ Centro de Tecnologia Mineral - CETEM - Av. Pedro Calmon, 900, Cidade Universitária - CEP: 21941-908, Rio de Janeiro, RJ e-mail: mmonte@cetem.gov.br
}

\section{RESUMO}

A oxidação da superfície da pirita é um problema sério na indústria de mineração, uma vez que diminui a sua hidrofobicidade dificultando a flotação desse mineral ou levando a um consumo elevado de coletor. Neste estudo, os produtos da reação entre os íons $\mathrm{Fe}^{2+}$ e $\mathrm{HS}^{-}$, formados na superfície da pirita oxidada e da hematita, foram estudados. As condições para a formação de uma camada hidrofóbica na superfície desses minerais também foram investigadas.

Avaliou-se a influência do $\mathrm{pH}$ das soluções de hidrossulfeto de sódio (NaHS) para atingir uma condição de $\mathrm{E}_{\mathrm{h}}-\mathrm{pH}$ adequada para a formação de compostos de enxofre hidrofóbicos nas superfícies minerais. Medidas de ângulo de contato, difração de raios-X (DRX), microscopia eletrônica de varredura/espectroscopia de energia dispersiva (MEV/EDS) e espectroscopia Raman foram as técnicas analíticas empregadas para se verificar a natureza dos produtos formados na superfície desses minerais.

Essas análises permitiram a identificação de cristais de enxofre elementar sobre a superfície da hematita e da pirita oxidada, após o condicionamento das amostras em meio redutor, e o melhor resultado foi obtido com condicionamento em pH 8,0 durante 96 horas com solução de NaHS 0,3 M para as duas amostras analisadas.

Palavras-chave: Hidrofobicidade, potencial redox, hematita, pirita.

\section{ABSTRACT}

The pyrite surface oxidation is a serious problem in the mining industry, since it decreases its hydrophobicity turning it difficult to float or leading to a high collector consumption. In this study, the products of the reaction between the $\mathrm{Fe}^{2+}$ and $\mathrm{HS}^{-}$, formed on the surface of oxidized pyrite and hematite, were studied. The conditions for the formation of a hydrophobic layer on the surface of these minerals were also investigated.

The $\mathrm{pH}$ influence of sodium hydrosulphide (NaHS) solutions was evaluated in order to achieve a suitable $\mathrm{E}_{\mathrm{h}^{-}}$ $\mathrm{pH}$ condition for the formation of hydrophobic sulfur compounds on mineral surfaces. Measurements of contact angle, X-ray diffraction (XRD), scanning electron microscopy/dispersive energy spectroscopy (SEM/EDS) and Raman spectroscopy were the analytical techniques used to verify the nature of the products formed on the surface of those minerals.

The formation of elemental sulfur crystals on the hematite and oxidized pyrite surfaces was identified after the conditioning in a reducing medium, and the best result was obtained at $\mathrm{pH} 8.0$ during 96 hours with a $0.3 \mathrm{M}$ NaHS solution for the two samples analyzed.

Keywords: Hydrophobicity, redox potential, hematite, pyrite. 


\section{INTRODUÇÃO}

A pirita $\left(\mathrm{FeS}_{2}\right)$ é distribuída em uma variedade de cenários geoquímicos e, por isso, geralmente é encontrada em associação com outros minerais de sulfeto e ouro e em depósitos de carvão. Por conta da sua importância em sistemas naturais e tecnológicos (processamento de carvão, flotação seletiva de sulfetos, formação e controle de drenagem ácida de mina) os estudos de formação e reatividade da pirita têm atraído a atenção e o envolvimento de diversos pesquisadores. A oxidação da superfície da pirita é um problema sério na indústria de mineração, uma vez que reduz sua hidrofobicidade, o que dificulta a flotação desse mineral ou propicia um consumo elevado de coletor [1,2].

A eficiência da flotação de sulfetos oxidados tem sido aumentada pela técnica de sulfetação com variados graus de sucesso. Uma característica comum a todas as superfícies sulfetadas é a presença de quantidades significativas de polissulfetos ou enxofre elementar, os quais podem contribuir para melhorar a flotação de sulfetos subsequente.

A sulfetação oferece oportunidades consideráveis para a restauração da hidrofobicidade de sulfetos que se tornam mais oxidados ou hidrofilicos. Newell et al. [3] reportaram algumas aplicações industriais, as quais incluíam o tratamento de sulfeto de níquel oxidado da Mina Trojan (Zimbabue) e da calcopirita oxidada processada nas operações da Mina de Nchanga (Zâmbia). Para eles, o mecanismo de sulfetação para minerais do tipo óxido metálico está associado à adsorção química do íon $\mathrm{HS}^{-}$para formar uma superfície de sulfeto, por meio de troca aniônica. Outros pesquisadores, como por exemplo, Wei e Osseo-Asare [4,5], atribuíram à precipitação de sulfetos metálicos na superfície do mineral o fundamento do mecanismo de sulfetação.

Os minerais de sulfeto respondem eficientemente à flotação conduzida na presença de coletores sulfidrílicos (grupamento tiol -HS). Em geral, quando o ligante tiol é dissociado da molécula, o mesmo reage com os cátions metálicos presentes na superfície do mineral, para formar complexos metálicos. O hidrossulfeto de sódio (NaHS) atua como ativador de sulfetos, em especial, quando os mesmos apresentam produtos de oxidação em suas superfícies, pois promove a precipitação de sulfetos metálicos e estabiliza a superfície mineral de interesse.

O objetivo geral deste trabalho foi o de avaliar o efeito na hidrofobicidade de amostras de pirita oxidada e hematita, esta última como forma de controle, em função dos seus condicionamentos em meio redutor e em valores de $\mathrm{pH}$ diferentes, através de medidas de ângulo de contato.

Os objetivos específicos desse trabalho são: avaliar o mecanismo de precipitação de espécies hidrofóbicas na superfície desses minerais, utilizando a técnica de espectroscopia Raman; identificar as espécies predominantes em solução e os possíveis produtos de reação através de diagramas de estabilidade $\mathrm{E}_{\mathrm{h}}-\mathrm{pH}$.

\section{MATERIAIS E MÉTODOS}

\subsection{Preparação e Caracterização das amostras}

Amostras naturais de hematita e pirita foram cortadas e em seguidas embutidas em resina epóxi. Após a etapa de embutimento as amostras tiveram uma seção transversal cortada, para tornar possível a leitura de ângulo de contato, e foram então polidas manualmente em duas etapas: a primeira com um feltro e uma suspensão de diamante de $3 \mu \mathrm{m}$, e a segunda com um feltro e uma suspensão de diamante de $1 \mu \mathrm{m}$.

Inicialmente, as amostras de hematita e pirita foram caracterizadas utilizando-se as técnicas de fluorescência de raios-X (FRX) e difratometria de raios-X (DRX).

\subsection{Determinação de ângulo de contato, microscopia eletrônica de varredura/espectroscopia de ener- gia dispersiva (MEV/EDS) e espectroscopia Raman}

A influência do $\mathrm{pH}$ na formação de compostos de enxofre hidrofóbicos nas superfícies minerais na condição de $\mathrm{E}_{\mathrm{h}}-\mathrm{pH}$ adequada foi avaliada. Medidas de ângulo de contato, microscopia eletrônica de varredura/espectroscopia de energia dispersiva (MEV/EDS) e espectroscopia Raman foram as técnicas analíticas empregadas para verificar a natureza dos produtos formados na superfície desses minerais. Essas análises foram realizadas antes e após o condicionamento em meio redutor, e, em particular, para as amostras de pirita após a etapa de oxidação.

O equipamento utilizado para análise por Raman da marca Horiba, modelo LabRam HR, possui um microscópio ótico Olympus BX41 acoplado que também permite a análise de imagens, um diferencial para essa técnica. 


\subsection{Oxidação da superfície das amostras de pirita}

As amostras naturais de pirita foram submetidas a uma forte oxidação com solução de peróxido de hidrogênio a 33\%, previamente ajustada para $\mathrm{pH} 5,5$ (com NaOH aquoso) por duas horas. A razão de amostra/solução utilizada foi de 1:20 (p/v), e a suspensão foi agitada manualmente.

\subsection{Ensaios de condicionamento em meio redutor}

Os ensaios de condicionamento em meio redutor foram adaptados para que a formação de enxofre fosse expressiva. Para isso utilizou-se apenas uma solução de NaHS 0,3 M e um tempo de contato de 96 horas com essa solução. Nesses ensaios o efeito do pH foi avaliado, para tal, empregou-se dois valores de pH: 8,0 e 10,0.

\section{RESULTADOS}

\subsection{Mineralogia e características químicas das amostras de hematita e pirita}

Os resultados semiquantitativos obtidos por fluorescência de raios-X (FRX) estão expressos em teores percentuais, calculados como óxidos e normalizados a 100\%, são apresentados na Tabela 1. A amostra de hematita utilizada nos ensaios possui um grau de pureza de $89,56 \%$ e o quartzo é a principal impureza presente nessa amostra. A amostra de pirita possui um teor de pureza mais elevado, 97,72\%.

Tabela 1: Análise por FRX das amostras naturais de hematita e de pirita.

\begin{tabular}{c|ccccc|c}
\hline AMOSTRA & \multicolumn{5}{|c|}{ TEORES (\%) } & GRAU DE PUREZA (\%) \\
\hline \multirow{2}{*}{ Hematita } & $\mathrm{Fe}_{2} \mathrm{O}_{3}$ & $\mathrm{Al}_{2} \mathrm{O}_{3}$ & $\mathrm{SiO}_{2}$ & $\mathrm{Cr}_{2} \mathrm{O}_{3}$ & $\mathrm{PPC}$ & 89,56 \\
& 89,20 & 0,75 & 9,50 & 0,15 & 0,00 & \multirow{2}{*}{97,72} \\
\hline \multirow{2}{*}{ Pirita } & $\mathrm{FeS}_{2}$ & $\mathrm{Al}_{2} \mathrm{O}_{3}$ & $\mathrm{SiO}_{2}$ & $\mathrm{CuO}$ & $\mathrm{WO}_{3}$ & 0,20 \\
& 97,50 & 0,13 & 1,70 & 0,24 & 0
\end{tabular}

A Figura 1(a) apresenta o difratograma obtido para a amostra de hematita. Essa análise revelou a hematita como mineral principal, mas foi possível identificar também o espectro de quartzo. Já a Figura 1(b) apresenta o difratograma obtido para a amostra de pirita utilizada nesses experimentos. Através dessa análise não foi possível identificar nenhum tipo de impureza na amostra de pirita, pois o único espectro que foi identificado foi o de pirita.
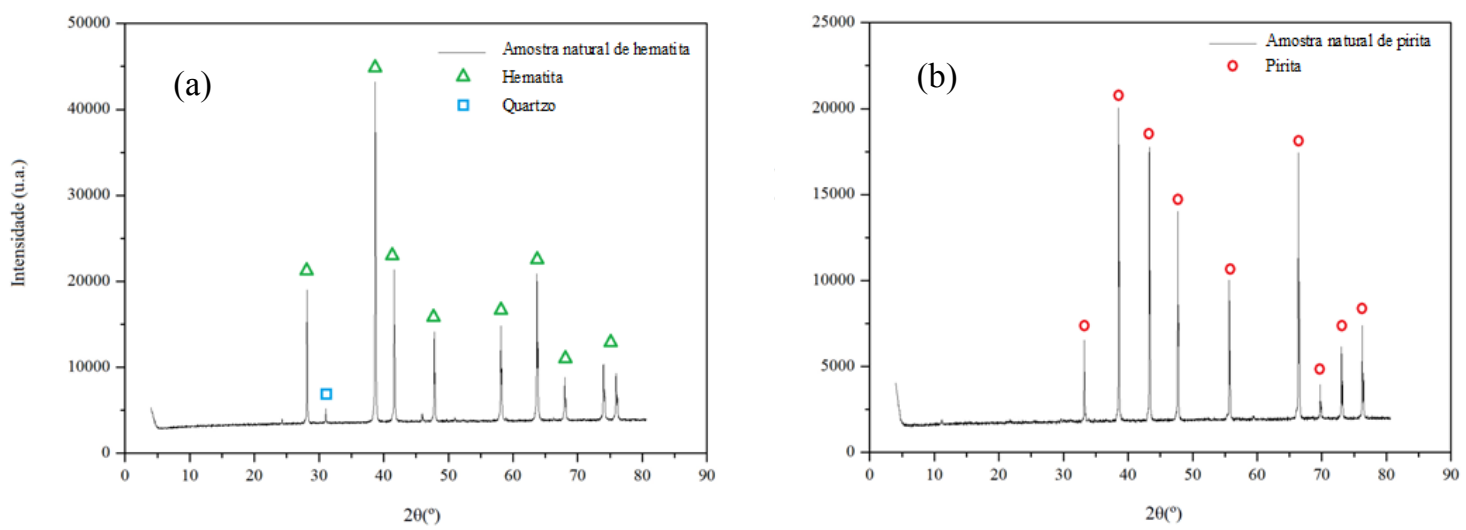

Figura 1: Difratogramas obtidos na caracterização das amostras: (a) hematita, (b) pirita.

\subsection{Efeito do condicionamento em NaHS na superfície de seções polidas - Formação de camada hidrofóbica}

A análise por espectroscopia Raman, antes e após o condicionamento em meio redutor, não revelou alterações nos espectros obtidos para as amostras de hematita, pois a posição dos picos $\left(\mathrm{E}_{\mathrm{g}}\right.$ em 245, 292, 411 e 612 
$\mathrm{cm}^{-1}$ e $\mathrm{A}_{1 \mathrm{~g}}$ em 226 e $499 \mathrm{~cm}^{-1}$ ) não foi alterada. Por outro lado, através das imagens obtidas no microscópio petrográfico acoplado ao Raman foi possível observar alterações na superfície dessas amostras depois da etapa de condicionamento com NaHS.
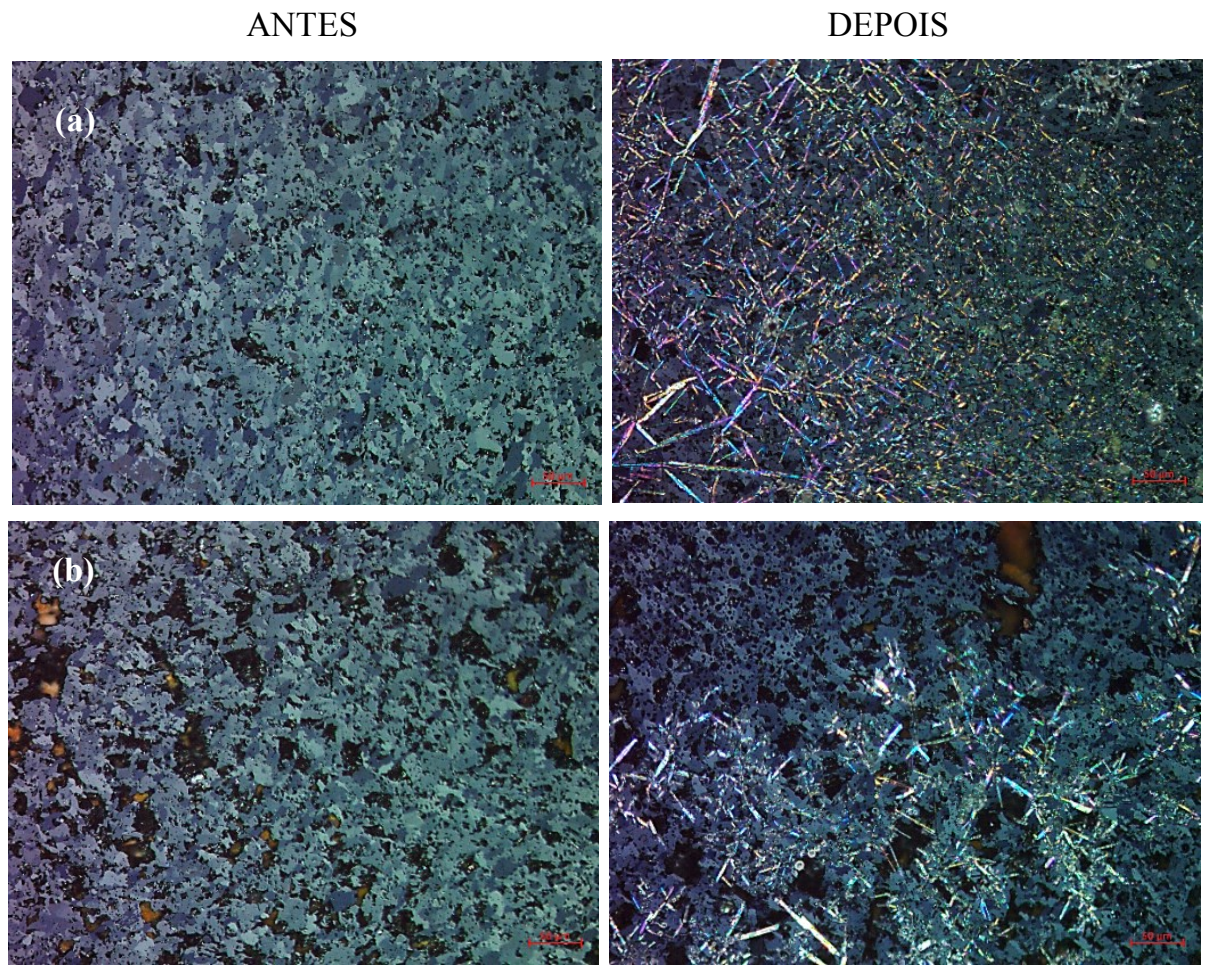

Figura 2: Imagens obtidas no microscópio óptico acoplado ao Raman das amostras de hematita antes e depois do condicionamento em meio redutor, com aumento de 10x. (a) Ensaio de 96h e pH 8,0; (b) Ensaio de 96h e pH 10,0.

A análise por microscopia eletrônica de varredura (MEV), antes e após o condicionamento em meio redutor, também revelou alterações na superfície das amostras de hematita. Ao utilizar um aumento nas imagens obtidas por elétrons retroespalhados foi possível identificar a formação de cristais na superfície dessas amostras, como pode ser visto na Figura 3. Através da análise de espectroscopia de energia dispersiva (EDS) comprovou-se uma alteração na composição dessas amostras, com ocorrência de enxofre, assim, foi possível constatar que os cristais formados na superfície das amostras de hematita eram de enxofre (Figura 4).
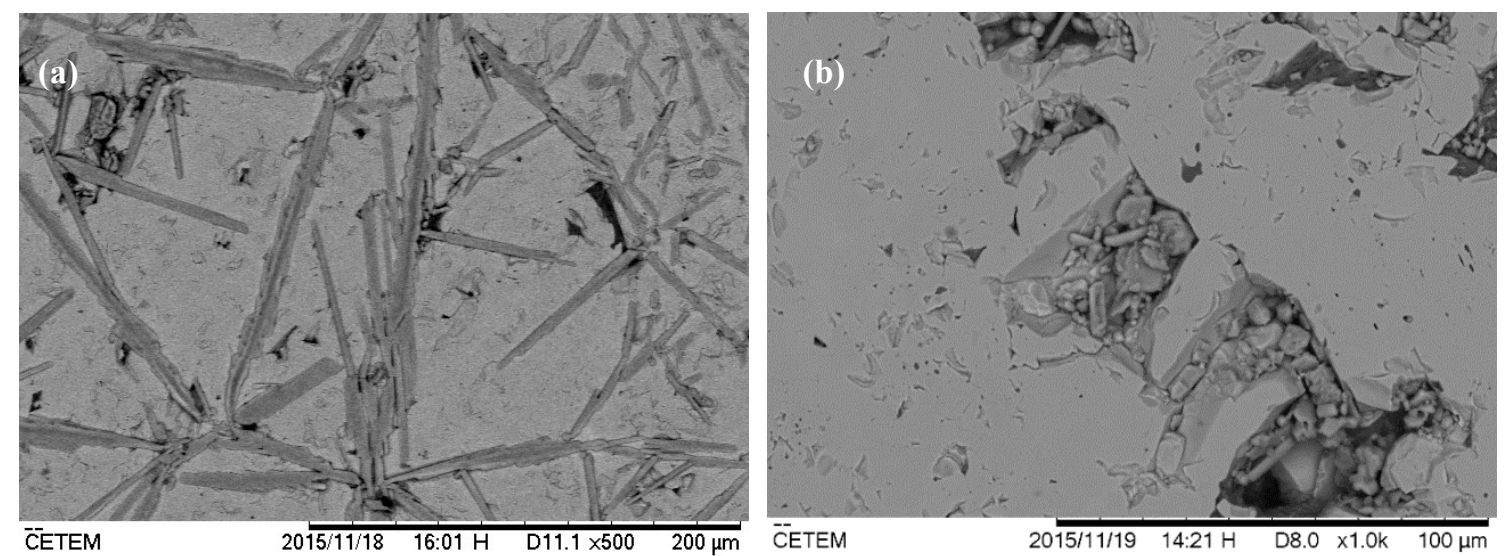

Figura 3: Imagens obtidas por elétrons retroespalhados das amostras de hematita depois do condicionamento em meio redutor-NaHS. (a) Ensaio de 96h e pH 8,0; (b) Ensaio de 96h e pH 10,0. 

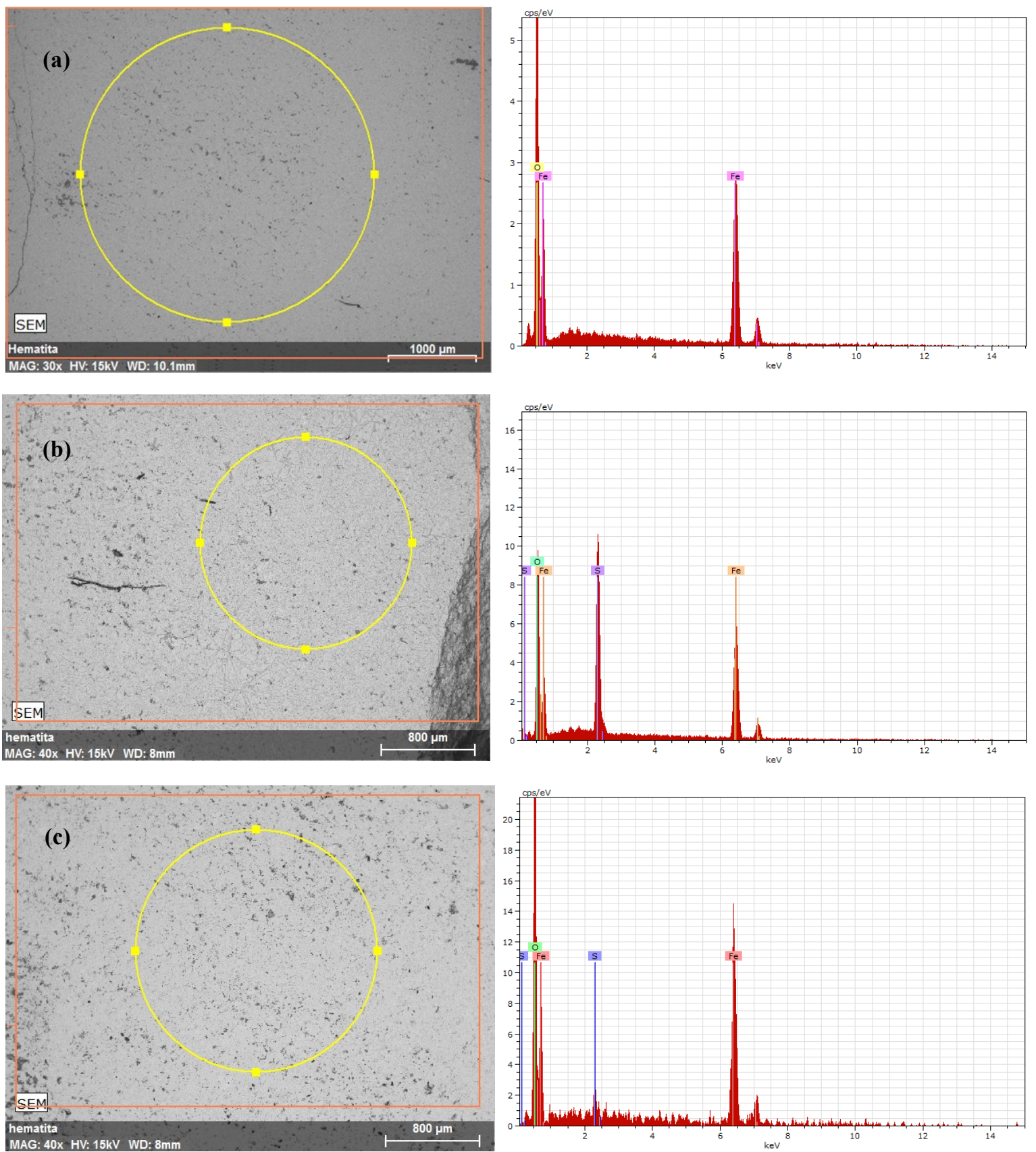

Figura 4: Imagens obtidas por elétrons retroespalhados e os respectivos espectros de EDS da amostra de hematita. (a) Etapa de Caracterização; (b) Etapa de condicionamento em meio redutor - pH 8,0; (c) Etapa de condicionamento em meio redutor $-\mathrm{pH} 10,0$.

Para as amostras de pirita, a análise por espectroscopia Raman, antes e após o condicionamento em meio redutor, revelou uma alteração nos espectros obtidos. Para as duas amostras foram identificados os picos referentes à pirita pura $\left(E_{\mathrm{g}} \mathrm{em} 343 \mathrm{~cm}^{-1}, \mathrm{Ag}_{\mathrm{g}} \mathrm{em} 379 \mathrm{~cm}^{-1} \mathrm{e} \mathrm{T}_{\mathrm{g}}\right.$ em $\left.430 \mathrm{~cm}^{-1}\right)$, mas para a amostra do ensaio condicionado em pH 10,0 os picos referentes ao enxofre elementar $\left(151,219\right.$ e $\left.473 \mathrm{~cm}^{-1}\right)$ também foram identificados.

Através das imagens obtidas no microscópio óptico acoplado ao Raman foi possível observar alterações na superfície das duas amostras após a etapa de condicionamento em meio redutor, como mostra a Figura 5. A formação de um depósito de formato acicular pode ser claramente observada, particularmente na amostra de pirita condicionada em $\mathrm{pH} 8,0$. 
ANTES
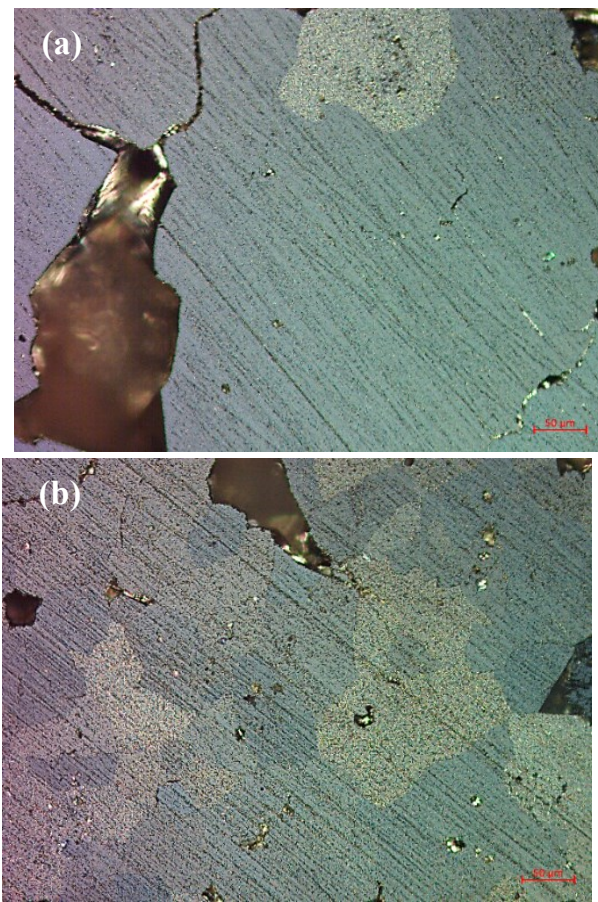

DEPOIS
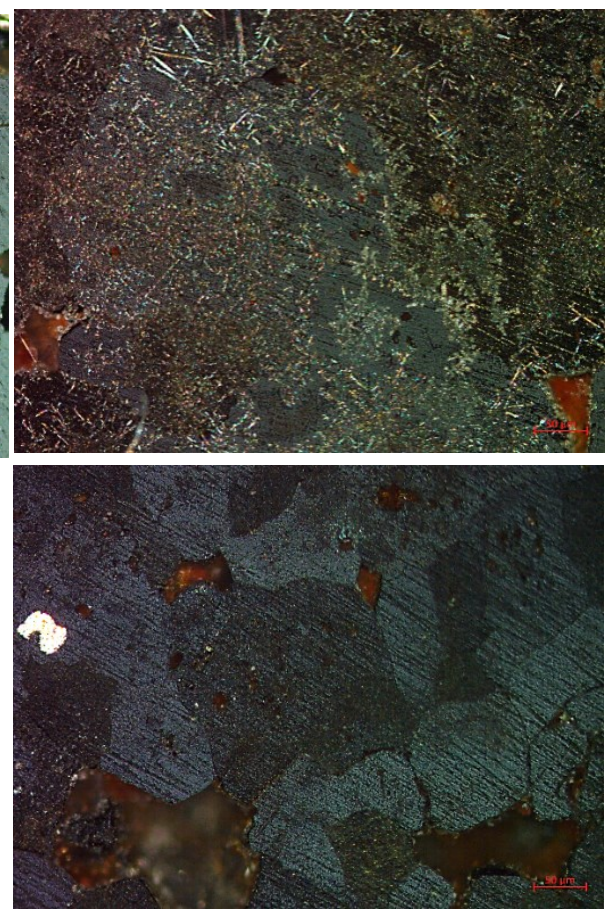

Figura 5: Imagens obtidas no microscópio petrográfico acoplado ao Raman das amostras de pirita oxidada, antes e depois do condicionamento em meio redutor, com aumento de 10x. (a) Ensaio de 96h e pH 8,0; (b) Ensaio de $96 \mathrm{~h}$ e $\mathrm{pH}$ 10,0 .

As imagens obtidas por elétrons retroespalhados, para um aumento de 1000x, das amostras de pirita são apresentadas na Figura 6. Como pode ser visto nesta figura, após o ensaio de condicionamento em meio redutor ocorreu a formação de cristais na superfície dessas amostras. Através da análise por espectroscopia de energia dispersiva (EDS) comprovou-se uma alteração na composição dessas amostras, pois o percentual de enxofre nas duas amostras aumentou, como pode ser observado na Figura 7. Com isso, foi possível constatar que os cristais formados na superfície das amostras de pirita eram de enxofre, mesmo efeito observado nas amostras de hematita.
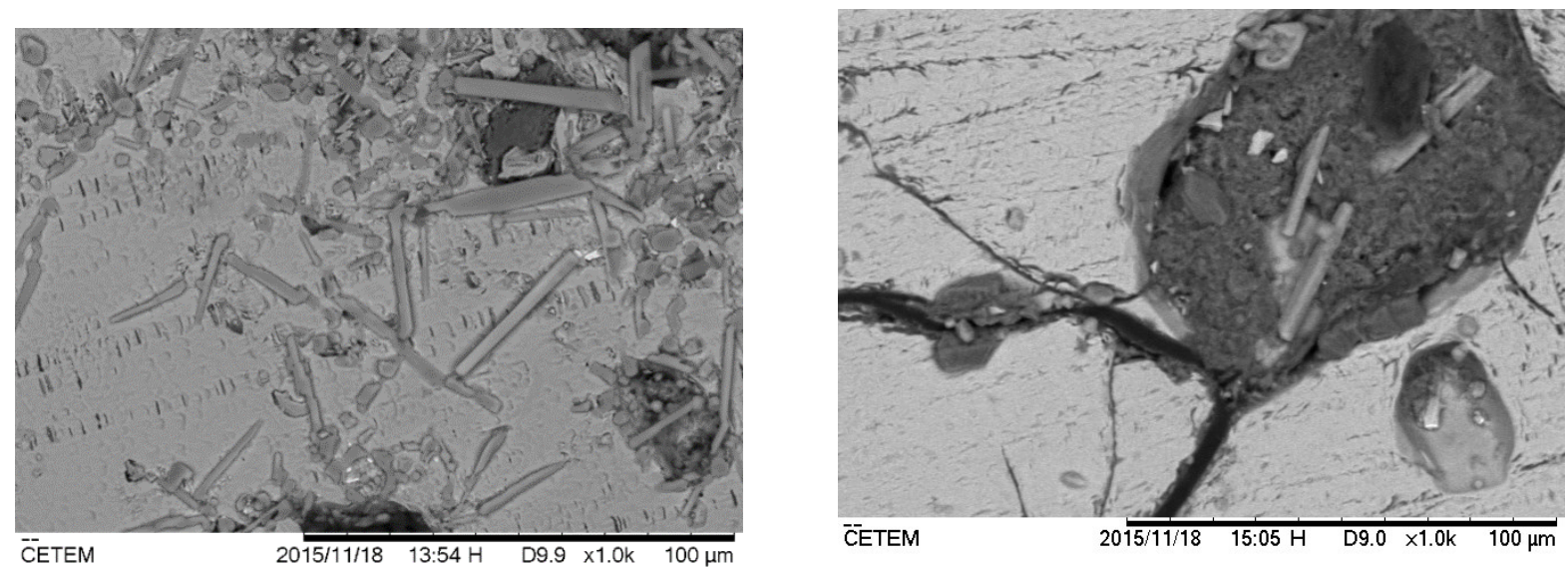

Figura 6: Imagens obtidas por elétrons retroespalhados das amostras de pirita depois do condicionamento em meio redutor-NaHS. (a) Ensaio de 96h e pH 8,0; (b) Ensaio de 96h e pH 10,0. 

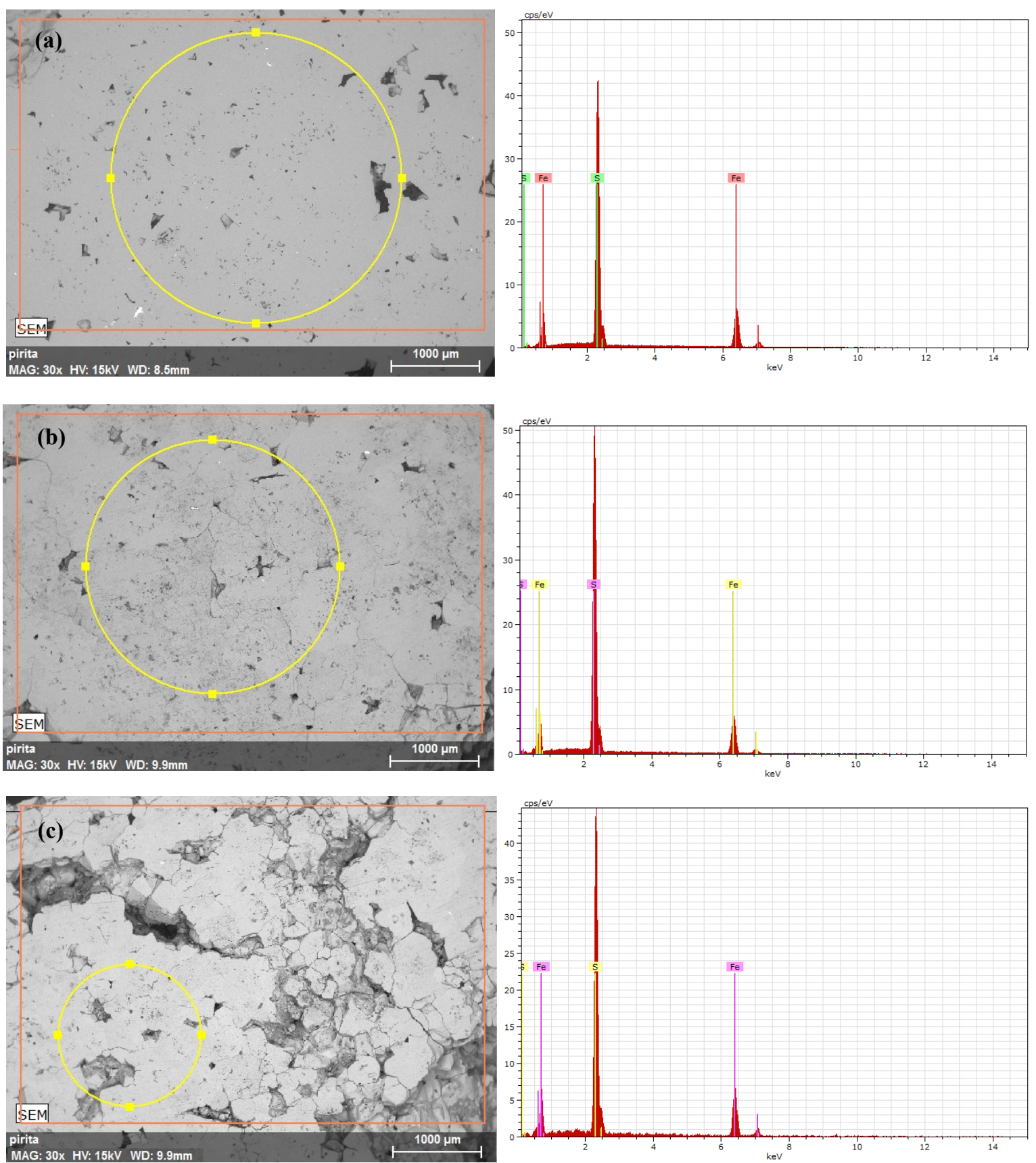

Figura 7: Imagens obtidas por elétrons retroespalhados e os respectivos espectros de EDS da amostra de pirita. (a) Etapa de Caracterização; (b) Etapa de condicionamento em meio redutor - pH 8,0; (c) Etapa de condicionamento em meio redutor $-\mathrm{pH} 10,0$.

\subsection{Efeito do condicionamento em NaHS na superfície de seções polidas - Hidrofobicidade}

$\mathrm{O}$ efeito do condicionamento em NaHS na hidrofobicidade da superfície da seção polida das amostras de hematita e pirita foi avaliado através da comparação dos resultados obtidos nas medições de ângulo de contato dessas amostras antes e após o condicionamento neste meio.

Para as amostras de hematita as medições de ângulo de contato foram feitas nas etapas de caracterização do mineral e após seu condicionamento em meio redutor. A comparação dos resultados é apresentada na Figura 8. As reações de formação de espécies mais hidrofóbicas, como enxofre e sulfetos, podem modificar a superfície dessas amostras, aumentando a hidrofobicidade das mesmas. Como pode ser observado, o aumento do valor do ângulo de contato ocorreu para as duas amostras condicionadas em $\mathrm{pH}$ diferentes. Além disso, podemos ver que em $\mathrm{pH} \mathrm{8,0} \mathrm{o} \mathrm{aumento} \mathrm{da} \mathrm{hidrofobicidade} \mathrm{foi} \mathrm{maior} \mathrm{do} \mathrm{que} \mathrm{em} \mathrm{pH} 10,0$. 


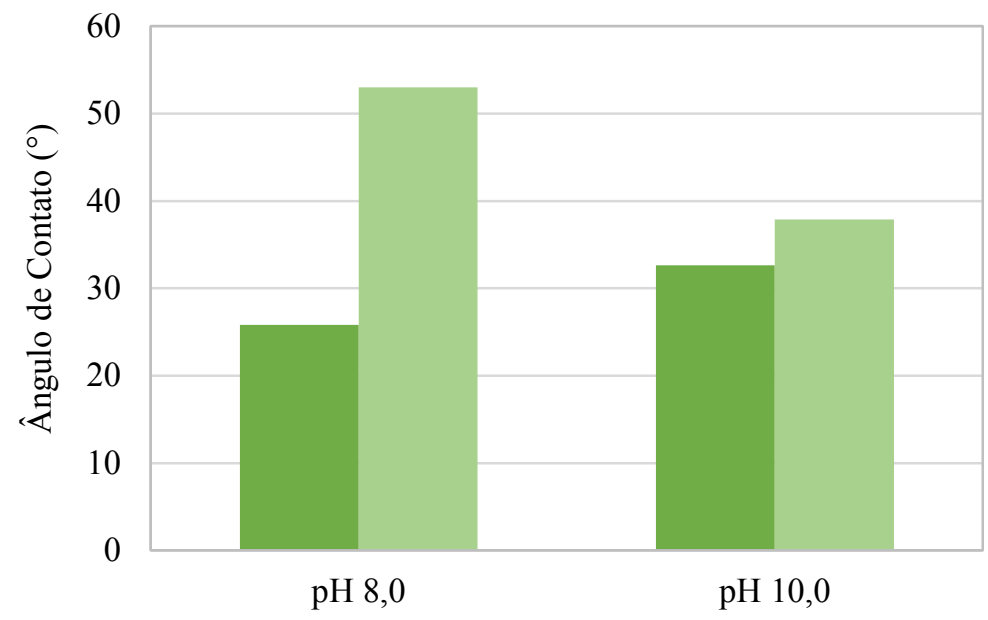

Hematita natural $\square$ Hematita após condicionamento em NaHS

Figura 8: Comparação das medições de ângulo de contato das amostras de hematita antes e após o condicionamento em meio redutor.

Para as amostras de pirita as medições de ângulo de contato foram feitas após as etapas de oxidação e de condicionamento em meio redutor. A comparação dos resultados é apresentada na Figura 9. Como pode ser observado o aumento do valor do ângulo de contato ocorreu apenas para a amostra condicionada em $\mathrm{pH}$ 10,0 .

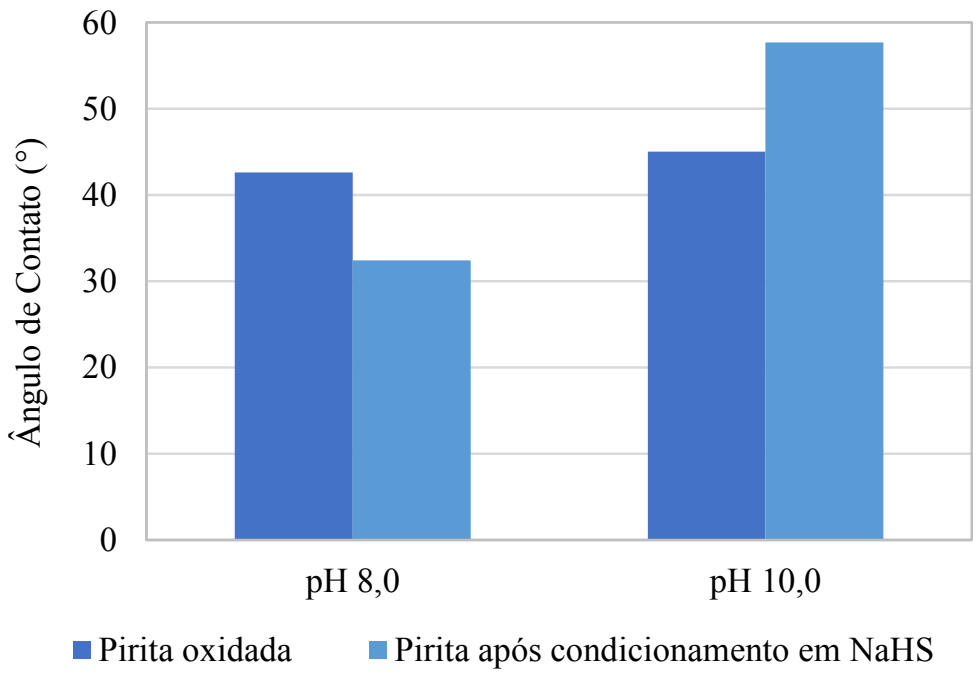

Figura 9: Comparação das medições de ângulo de contato das amostras de pirita oxidada antes e após o condicionamento em meio redutor.

\section{DISCUSSÃO}

Nos ensaios de condicionamento em meio redutor com as amostras de hematita e de pirita houve a formação de alguns cristais, como pôde ser observado nas imagens obtidas por microscopia Raman e por MEV, além disso, através da análise por EDS foi possível verificar que esses cristais eram de enxofre. Contudo, a partir das análises realizadas não foi possível constatar se houve ou não formação de pirita em algum dos ensaios, apenas comprovou-se a formação de enxofre sobre a superfície das amostras de hematita e de pirita.

Para elucidar os resultados obtidos foi elaborado um diagrama $\mathrm{E}_{h}-\mathrm{pH}$ para o sistema $\mathrm{Fe}-\mathrm{S}-\mathrm{H}_{2} \mathrm{O}$, considerando a temperatura ambiente $\left(25^{\circ} \mathrm{C}\right)$, para avaliar os possíveis produtos de formação do sistema NaHS e hematita/pirita. Como pode ser visto na Figura 10, a região de pirita $\left(\mathrm{FeS}_{2}\right)$ ocorre em toda a faixa de $\mathrm{pH}$ (en- 
tre 0 e 14) e numa faixa de $E_{h}$, entre $-0,50$ e 0,30 Volts. Como pôde ser visto, no ensaio em que o pH foi ajustado em 8,0 o pH final da solução era igual a aproximadamente 9,0 ; já no ensaio em que o $\mathrm{pH}$ foi ajustado em 10,0 o pH final da solução era igual a aproximadamente 11,0; e por isso, era esperado a formação de pirita.

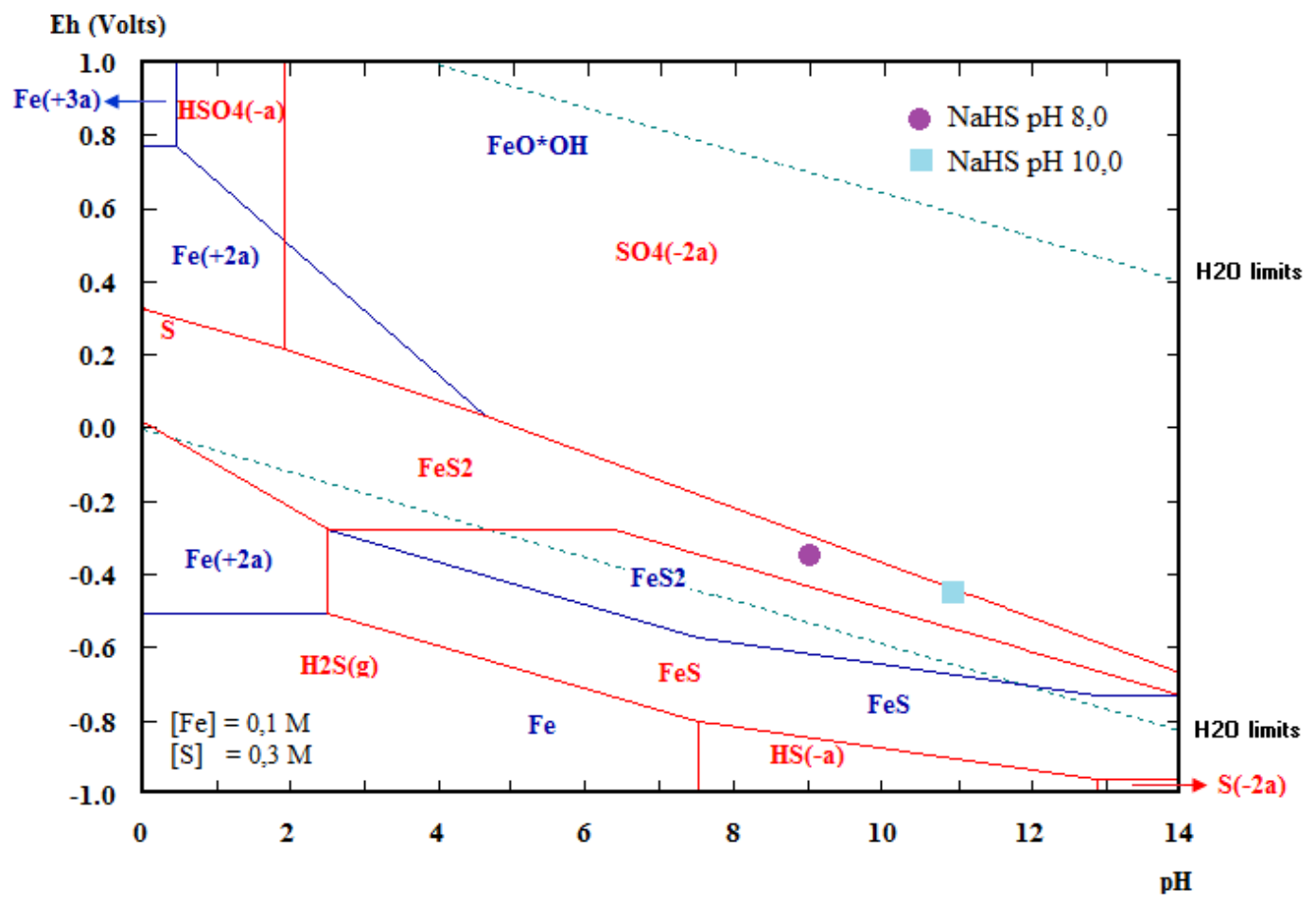

Figura 10: Diagrama $\mathrm{E}_{h}-\mathrm{pH}$ para o sistema $\mathrm{Fe}-\mathrm{S}-\mathrm{H}_{2} \mathrm{O}$ a $25^{\circ} \mathrm{C}$.

Pôde-se verificar que a concentração de ferro na solução era muito baixa em todos os ensaios, em contrapartida, a formação de enxofre foi favorecida em todos os ensaios. Com esses resultados, acredita-se que o tempo de contato com a solução não tenha sido suficiente para que mais partículas de ferro fossem dissolvidas, impedindo que a reação de formação de pirita ocorresse, pois, segundo Wei e Osseo-Asare [3], a formação de pirita exige como precursores tanto o monossulfeto de ferro (II) (ou $\mathrm{Fe}(\mathrm{HS})^{+}$) quanto o enxofre elementar (ou íons de polissulfeto).

Constatou-se também que as condições dos ensaios para as amostras de hematita e de pirita foram favoráveis para o processo de cristalização (Figuras 3 e 6). Segundo a literatura $[6,7,8]$, a cristalização ocorre em duas etapas: nucleação e crescimento. A etapa de nucleação é caracterizada pelo aparecimento de pequenas regiões com arranjo ordenado de átomos ou moléculas; já a etapa de crescimento ocorre nestas regiões, após elas se estabilizarem como núcleos da nova fase e, então, ocorre a formação dos cristais.

De acordo com os conceitos de nucleação, nesses ensaios de condicionamento em meio redutor ocorreu o processo de nucleação heterogênea, no qual a transformação ocorre sobre sítios favoráveis (substratos), que são catalisadores do processo de nucleação, sendo que os sítios favoráveis foram: a superfície da amostra de hematita, que não continha imperfeições (Figura 3); e os contornos, imperfeições e buracos das amostras de pirita, que são energeticamente mais favoráveis para a nucleação de uma nova fase (Figura 6) [6,7,8].

Outra consideração importante a ser feita é a respeito do enxofre formado em todos os ensaios de condicionamento em meio redutor com NaHS. Segundo a literatura [9], o enxofre possui duas variedades alotrópicas principais: na natureza o enxofre ocorre normalmente na forma de cristal ortorrômbico; por outro lado, dois polimorfos monoclínicos são muito raros na natureza, mas são comumente produzidos sinteticamente. Esses alótropos não se diferenciam pela atomicidade, ambos possuem a fórmula molecular $\mathrm{S}_{8}$, o que os diferencia é o arranjo espacial dos átomos. Portanto, através das imagens obtidas por elétrons retroespalhados e de acordo com a literatura, os cristais formados sobre a superfície das amostras de hematita e de pirita são cristais de enxofre monoclínico, de formato acicular. 


\section{CONCLUSÕES}

Pode-se concluir que o objetivo geral deste trabalho foi alcançado e através das medições de ângulo de contato foi possível constatar que após o condicionamento das amostras de hematita e de pirita oxidada em meio redutor, a superfície dessas amostras foi modificada, uma vez que, ocorreu um aumento do grau de hidrofobicidade das mesmas.

Nos ensaios de condicionamento em meio redutor pôde-se verificar também que o $\mathrm{pH}$ é um fator que afeta a formação de espécies hidrofóbicas (cristais de enxofre). O melhor resultado para a hematita foi obtido na condição de $\mathrm{pH} 8,0$, quando o ângulo de contato aumentou de $26^{\circ}$ para $53^{\circ}$ após o condicionamento em meio redutor. Já para a pirita, o melhor resultado foi obtido na condição de $\mathrm{pH} 10,0$, quando o ângulo de contato aumentou de $45^{\circ}$ para $58^{\circ}$ após o condicionamento.

\section{AGRADECIMENTOS}

Os autores agradecem a todos que auxiliaram no desenvolvimento das metodologias e na preparação e caracterização das amostras, ao Centro de Tecnologia Mineral (CETEM) e ao Programa de Engenharia Metalúrgica e de Materiais da COPPE/UFRJ por fornecerem todas as condições para a realização dos experimentos realizados nesse trabalho.

\section{BIBLIOGRAFIA}

[1] MONTE, M.B.M., LINS, F.F., OLIVEIRA, J.F., "Selective flotation of gold from pyrite under oxidizing conditions", International Journal of Mineral Processing, v. 51, pp. 255-267, 1997.

[2] MONTE, M.B.M., DUTRA, A.J.B., ALBUQUERQUE JR., et al., "The influence of the oxidation state of pyrite and arsenopyrite on the flotation of an auriferous sulphide ore", Minerals Engineering, v. 15, pp. 1113-1120, 2002.

[3] NEWELL, A.J.H., SKINNER, W.M., BRADSHAW, D.J., Restoring the floatability of oxidised sulfides using sulfidisation", International Journal of Mineral Processing, v. 84, pp. 108-117, 2007.

[4] WEI, D., OSSEO-ASARE, K., "Particulate pyrite formation by the Fe3+/HS- reaction in aqueous solutions: effects of solution composition", Colloids and Surfaces, v. 118, pp. 51-61, 1996.

[5] WEI, D., OSSEO-ASARE, K., "Aqueous synthesis of finely divided pyrite particles", Colloids and Surfaces, v. 121, pp. 27-36, 1997.

[6] KASHCHIEV, D., Nucleation: Basic Theory with Applications, Oxford/ Auckland/ Boston/ Johannesburg/ Melbourne/ New Delhi, Butterworth Heinemann, 2000.

[7] MULLIN, J., "Nucleation", In: Crystallization, chapter 5, Oxford/ Boston/ Johannesburg/ Melbourne/ New Delhi/ Singapore, Butterworth Heinemann, 2001.

[8] SCHMELZER, J.W.P. Nucleation Theory and Applications, Weinheim, WILEY-VCH Verlag GmbH \& Co. KGaA, 2005.

[9] KLEIN, C., "Crystal Chemistry and Systematic Descriptions". In: The 22nd Edition of The Manual of Mineral Science, chapters 8 e 9, New York/ Chichester/ Weinheim/ Brisbane/ Singapore/ Toronto, John Wiley \& Sons, Inc., 2002.

[10] DUQUE, T.F.M.B., Influência do condicionamento em meio redutor na hidrofobicidade da hematita e da pirita oxidada, Dissertação de M.Sc., COPPE/UFRJ, Rio de Janeiro, RJ, Brasil, 2016. 